\title{
The Heterogeneous Impact of International Migration on Left-behind Households: Evidence from Bangladesh
}

\author{
Donato Romano* and Silvio Traverso**
}

\begin{abstract}
This article investigates the heterogeneous effects of international migration on the expenditure of Bangladeshi migrant households. Adopting a counterfactual framework, we estimate the impact of migration on per capita expenditure of left-behind households according to their position in the counterfactual expenditure distribution and the length of the migration period. The effects on households' social mobility and on inequality are also assessed. The analysis indicates that migration has a positive impact on per capita expenditure and represents an important vehicle of social mobility, but may also be a source of inequality. We also find that only a tiny share of international migrants originates from households belonging to the lowest expenditure quintile and, since most of the characteristics which seem to influence the migration decision cannot be shaped by policy interventions, our results also suggest that pro-migration policies might not be effective in lifting those most in need out of poverty.
\end{abstract}

\section{INTRODUCTION}

Over the last two decades, the development potential of international migration has been emphasized both theoretically and empirically (De Haas, 2012). An ever-increasing literature shows that migration can affect many dimensions of household welfare through different channels, such as household composition changes, monetary and social remittances. Despite the evidence on the effects of migration on household inequality (Barham and Boucher, 1998; Brown and Jimenez, 2008; Antman, 2015; Mangiavacchi et al., 2018), children's education (Giannelli and Mangiavacchi, 2010; Acosta, 2011; McKenzie and Rapoport, 2011) and mental health of the left-behinds (Graham et al., 2015; Wickramage et al., 2015) is mixed, the overall poverty-reduction effect of international migration has been documented in several microeconomic studies (e.g. Lokshin et al., 2010; Jimenez-Soto and Brown, 2012; Adams and Cuecuecha, 2013; Bertoli and Marchetta, 2014; Combes et al., 2014). In addition, migration and remittances may play a positive role in other dimensions of household welfare, like left-behinds' physical health status (Azzarri and Zezza, 2011; Carletto et al., 2011; Böhme et al., 2015) and food consumption patterns (Karamba et al., 2011; Nguyen and Winters, 2011).

Since the mid-1990s, international migration has become a common strategy among Bangladeshi households to improve their welfare and during the 2000s Bangladesh became one of the most

\footnotetext{
* University of Florence, Florence, Italy
}

** University of Trento, Trento, Italy 
important migrant-sending countries (United Nations, 2013). While the literature on the effects of migration and remittances in Bangladesh is vast (e.g., Siddiqui, 2003; Mendola, 2008; Chowdhury, 2011; Siddique et al., 2012; Hassan et al., 2016), to the best of our knowledge, no study so far has estimated the impact of international migration on expenditure of left-behind Bangladeshi households using a nationally representative data set. In addition, we analyse the factors that are likely to determine the selection of migration and, adopting a counterfactual framework, we assess possible heterogeneous effects across different groups of migrant households.

Our analysis indicates that international migration has, on average, a positive and significant effect on the level of per capita expenditure of left-behind households. However, the relative gain in per capita expenditure turns out to be inversely related to the original households' expenditure quartile and it becomes not statistically significant for migrants originating from the top quartile. Moreover, the effect is stronger for households with a longer migration experience. International migration also represents an important driver of social mobility: in about half of the cases migrant households were able to climb the social ladder by at least a quintile while, on the other hand, one out of four migrant households fell back to a lower quintile. Finally, our analysis also suggests that international migration is a strategy that is largely not available to (or suitable for) the poorest segments of the population. This finding has important policy implications. Indeed, since several factors that affect the migration decision cannot be changed by policy interventions (e.g., those related to the demographic structure of the household), we argue that the policies aimed at reducing the cost of workers' migration may fail to help the poorest among the poor.

The rest of the article is organized as follows. The next section briefly describes the Bangladesh context, then we introduce data and illustrate the empirical strategy; next, we discuss the results and some policy implications. The last section recaps the main findings and concludes.

\section{THE BANGLADESH CONTEXT}

During the 1970s and the 1980s, Bangladesh was in dire straits. Dubbed as an international 'basket case' (The Economist, 2012), the country was characterized by widespread poverty and political instability. However, since the early 1990s, the country managed to make significant progress in terms of several social indicators and also, from the beginning of the new millennium, in terms of economic growth.

The growth of real incomes and the remarkable improvements in terms of health and food security have been welcomed by some scholars as the "Bangladesh surprise" (Mahmud, 2008; Asadullah et al., 2014). During this period, the economy and the whole of Bangladeshi society went through a deep transformation in which international migration played a prominent role (Bangladesh Bank, 2013). Indeed, averaging a net outflow of more than half a million of migrants per year between 2000 and 2010, Bangladesh was the country that contributed the most, in absolute terms, to the international migration flows of that decade (United Nations, 2013) and, according to our dataset, in 2011 almost one out of nine Bangladeshi households had some direct experience of international migration. Not surprisingly, the increase in the stock of international migrants went hand in hand with a boost in overseas remittances, which outweighed official development assistance and FDI already in mid-1990s (Mohapatra et al., 2010) peaking at a remarkable 12.2 per cent of GDP in 2012.

In Bangladesh, the link between migration and development dynamics is evident. Low domestic wages, overpopulation and environmental vulnerability worked jointly as push factors for outward migration, which became an increasingly common welfare-improving strategy for the Bangladeshi households (Siddiqui, 2003). Migration has also been an important determinant of the country's recent social and economic development. For example, overseas remittances have fostered the 
development of the financial sector (Chowdhury, 2011) and positively contributed to long-run output growth (Siddique et al., 2012; Kumar and Stauvermann, 2014), although their impact on total factor productivity is mixed (Hassan et al., 2016). Moreover, international migration helped rural households to innovate farming technology (Mendola, 2008) and enhance household resilience to shocks (Sikder and Higgins, 2017). In general, however, the impact of international migration on Bangladesh society went well beyond the economic dimension, contributing to shape the ideals of personal growth and self-realization of an entire generation of Bangladeshis (Gardner, 2009).

\section{DATA}

The study employs the data collected during the $15^{\text {th }}$ round of Bangladesh Household Income and Expenditure Survey (HIES), held between February 2010 and January 2011. The survey, which represents the primary source of social and economic data on Bangladesh households, is nationally representative and has been conducted by the Bangladesh Bureau of Statistics in collaboration with the World Bank. In its 2010-2011 version, HIES covered 12,240 households (55,580 individuals). The survey questionnaire includes sections on expenditure, income, consumption, education, employment, health, households' assets and - among others - migration. The module on migration gathers an additional set of information on 1,372 international and 728 domestic individual migrants who, before migrating, were part of the surveyed households.

In our analysis, an international migrant household is defined as a household meeting at least one of the two following conditions: (i) the household currently has one (or more) member migrated abroad; (ii) one (or more) member of the household has been abroad for more than six consecutive months during the previous 5 years. The latter condition makes it possible to consider as migrant households those households whose welfare is likely to be currently affected by the migration experiences occurred in their recent past (Hadi, 2001).

According to the above definition, 10.4 per cent of Bangladeshi households can be classified as "international migrant". It turns out that, among households meeting condition (i), the average number of migrants is 1.18 and virtually all of them (98.4\%) are male. In general, the share of migrant households receiving remittances the year before the survey was 82.0 per cent, but it increases to 91.7 per cent when only the subgroup of migrant households which meets condition (i) are considered.

Comparing migrant and non-migrant households (Table 1), we can see that on average the former households are larger, more likely to live in rural areas and more land-endowed than the latter. Moreover, while adult males have a lower level of education, adult females belonging to migrant households turn out to be, on average, more educated than those of non-migrant households.

\section{EMPIRICAL STRATEGY}

\section{Measuring household expenditure}

This research considers the wellbeing of individuals in terms of their command over goods and services, i.e. per capita expenditure ${ }^{1}$ :

$$
Y_{i}=e\left(\mathbf{p}, u_{i}\right) / d\left(\mathbf{x}_{i}\right)
$$

where $e($.$) is the household expenditure function, d($.) the equivalence scale function, $\mathbf{p}$ a vector of the prices of all the goods and services available in the market, $\mathbf{x}$ a vector of relevant household 
TABLE 1

HOUSEHOLDS' DESCRIPTIVE STATISTICS

\begin{tabular}{|l|cccr|}
\hline & Overall & Non-migrant & Migrant & Matched \\
\hline Household size & 4.65 & 4.51 & 5.89 & 5.96 \\
Kids (aged 6-17) & 1.29 & 1.28 & 1.40 & 1.39 \\
Male adults (aged 18-45) & 0.98 & 0.91 & 1.58 & 1.63 \\
Male adults (aged 46-65) & 0.34 & 0.33 & 0.42 & 0.42 \\
Female adults (aged 18-45) & 1.02 & 1.00 & 1.19 & 1.17 \\
Female adults (aged 46-65) & 0.30 & 0.29 & 0.44 & 0.46 \\
Elderly (aged 66+) & 0.19 & 0.18 & 0.25 & 0.26 \\
Years of education, adult males & 4.36 & 4.37 & 4.28 & 4.66 \\
Years of education, adult females & 3.63 & 3.52 & 4.50 & 4.55 \\
Urban (municipality) & $26.80 \%$ & $27.02 \%$ & $24.94 \%$ & $24.48 \%$ \\
Urban (metropolitan area) & $9.15 \%$ & $9.48 \%$ & $6.35 \%$ & $7.23 \%$ \\
Muslim & $87.79 \%$ & $86.94 \%$ & $94.97 \%$ & $95.22 \%$ \\
Landless & $6.38 \%$ & $6.85 \%$ & $2.40 \%$ & $2.35 \%$ \\
Quasi-landless (<0.05 acres) & $23.25 \%$ & $24.60 \%$ & $11.85 \%$ & $11.83 \%$ \\
Number of observations & 12,240 & 10,949 & 1,291 & 3,873 \\
\hline
\end{tabular}

Note: Descriptive statistics do not include migrant members. The last column reports the statistics of the households matched to migrant households.

characteristics and $u$ the (maximized) level of utility of the household. Total expenditure is defined by function $e$, which is nondecreasing, continuous, concave and homogeneous of degree 1 in $p$. The equivalence scale function $d$ is meant to standardize household size according to household characteristics, making comparable the welfare of individuals belonging to households which differ in their demographic composition.

Per capita expenditure has been estimated aggregating data from daily, weekly, monthly and annual consumption modules of the survey. As it was not possible to implement a rental equivalent approach, the consumption flow of durable goods has been estimated assuming an annual depreciation rate of 10 per cent (Deaton and Zaidi, 2002). The equivalence scales adopted in the analysis are the OECD Oxford scale, the OECD modified scale and the square root scale, as described in OECD (2013). ${ }^{2}$

\section{Counterfactual framework and treatment effect}

The evaluation of the impact of international migration on household welfare requires the estimation of a no-migration counterfactual scenario. The key assumption behind a counterfactual analysis is that every unit belonging to the population of interest has a potential outcome under each treatment state. Within such a framework, the impact of the exposure to a treatment (with respect to the exposure to an alternative set of causes) on a given unit is the difference between the outcomes associated to the two treatment states. In the case of a binary treatment (i.e., migration/no-migration), the observational rule for the outcome of the variable of interest $Y$ can be formalized as:

$$
Y_{i}^{\mathrm{obs}}=\mathrm{D}_{i} Y_{i}^{(1)}+\left(1-\mathrm{D}_{i}\right) Y_{i}^{(0)}
$$

where $Y_{i}^{(0)}$ and $Y_{i}^{(1)}$ indicate the two potential outcomes of the variable of interest for the $i$-th observation and the dummy variable $\mathrm{D}_{i}$ indicates the exposure to one of the two alternative treatment states. In the present analysis, the variable of interest is the logarithm of per capita expenditure, computed at the household level through relation (1) while the treatment is given by the migration status of the household. 
The individual treatment effect on the treated units, is defined as:

$$
\tau_{i}^{\text {treat }}=\left(Y_{i}^{(1)}-Y_{i}^{(0)} \mid \mathrm{D}_{i}=1\right)
$$

while the average treatment effect on the treated (ATT), that is the expected value of $\tau_{i}^{\text {treat }}$, is defined as:

$$
\mathrm{ATT}=E\left(Y_{i}^{(1)}-Y_{i}^{(0)} \mid \mathrm{D}_{i}=1\right)
$$

that is the average impact of migration on the welfare of the members of migrant households.

In order to estimate the effect of migration on households belonging to different quartiles of expenditure or characterized by a different length of exposure to the treatment, the expected value of the treatment effect is conditioned not only on the exposure to the treatment, but also on the set of conditions $\Theta_{i}$. The resulting estimator is defined as:

$$
\operatorname{ATT}_{\mid \Theta}=E\left(\mathrm{Y}_{i}^{(1)}-\mathrm{Y}_{i}^{(0)} \mid \mathrm{D}_{i}=1, \Theta_{i}\right)
$$

where $\Theta$ is the set of additional conditions, e.g. the quartile of expenditure of the household in the counterfactual scenario.

\section{Matching}

The microeconomic evaluation of the impact of migration on the welfare of the left-behind raises a series of methodological issues (Adams, 2011) such as self-selection of migrants, reverse causality between poverty and migration, omitted/unobservable variables, and simultaneity of the migration decision with other household-level choices (e.g. labour supply, education, fertility) that may also influence the outcome variable.

In the case of observational studies, regression-based approaches represent the most common methodological solution. Regression-based approaches relate causality with the notion of ceteris paribus and the treatment effect is typically estimated as the coefficient of a migration dummy. The above-mentioned methodological issues are usually addressed by resorting to instrumental variables (IV). For instance, Böhme et al. (2015) instrumented migration by interacting local historical migration patterns with growth rates of destination countries, McKenzie et al. (2010) exploited the distance of household's residence from Tonga's immigration office and, in a study on the effects of migration on household members' labour supply Mendola and Carletto (2012) employed (together with other network-related instruments) an IV based on the gender composition of the households. None of these instruments, however, could be applied in our work. On the one hand, the lack of high-resolution information on historical migration patterns prevented us from following the approach of Böhme et al. (2015). ${ }^{3}$ On the other hand, the strategy adopted by McKenzie et al. (2010) is not suitable for our analysis because it requires that all the sample households belong to the same labour market whereas the number of working-age male members, employed as IV by Mendola and Carletto (2012), may be considered exogenous to individual employment outcomes but clearly affects our dependent variable, i.e. the level of per capita expenditure. Hence, we resorted to matching methods.

Matching has been employed in a number of migration studies (Ham et al., 2011; Jimenez-Soto and Brown, 2012; Bertoli and Marchetta, 2014; Möllers and Meyer, 2014) and, as showed by McKenzie et al. (2010), it represents the best alternative to IV when good instruments are not 
available. ${ }^{4}$ Unlike regression-based approaches, matching methods emphasise the importance of common support, i.e. the notion that the treatment and the control groups should exhibit the same distribution of the relevant confounding variables (Cox, 1992). ${ }^{5}$ Moreover, and importantly, matching estimates are non-parametric and therefore, do not rely on any specific functional form, matching is more suitable than regression for estimating a counterfactual scenario and for studying heterogeneous effects.

The key identification assumption of matching methods is selection on observables (SO), which requires that, after conditioning on a balancing score that is a function of an appropriate set of exogenous and observable covariates $\mathbf{X}$, potential outcomes are orthogonal to selection into treatment. ${ }^{6}$ Therefore, the choice of the set of covariates $\mathbf{X}$ of the probability model used to estimate the balancing score represents a crucial step of the estimation procedure and for this reason we discuss the inclusion of each group of matching covariates in the next section.

Following Imbens and Rubin (2015), we perform matching on the linearized propensity score (lps), defined as the logarithm of the odds of the propensity score:

$$
\ell\left(\mathbf{X}_{i}\right)=\log \left(\frac{P S\left(\mathbf{X}_{i}\right)}{1-P S\left(\mathbf{X}_{i}\right)}\right)
$$

where $\mathbf{X}_{i}$ is the vector of the conditioning variables of the $i$-th observation and $P S\left(\mathbf{X}_{i}\right)$ is the propensity score, that we estimate by means of a probit model. By removing the non-linearity of the propensity score, the lps ensures the consistency of the matching estimators, such as nearest neighbour, radius, kernel, that are based on the linear distances between scores (Rubin, 2001; Imbens and Rubin, 2015).

\section{The selection of matching covariates}

In this section, we discuss the covariates that will be included in the probability model used to estimate the propensity score. Broadly speaking, matching covariates need to be relevant and exogenous. Covariates are relevant when they simultaneously influence both the probability of the selection into the treatment (i.e., migration) and the outcome of interest (i.e., per capita expenditure). On the other hand, exogeneity requires the absence of any causal relationship between the treatment and the covariates. In this regard, as a general rule of thumb, the covariates already realized before the exposure to the treatment (i.e., pre-treatment characteristics) can generally be regarded as exogenous.

As widely acknowledged by the literature, the household demographic structure is key in influencing both the migration decision and the level of expenditure. ${ }^{7}$ Hence, our set of covariates includes the number of working age male and female members (divided in two age groups, 18-45 and 46-65), the number of elderly and the number of children between 6 and 17 years old. Considering that migration may affect fertility choices, we did not include children younger than six because their number is likely to be endogenous to the migration status of the household. Accordingly, neither the household size, used by Jimenez-Soto and Brown (2012), nor the age dependency ratio, used by Bertoli and Marchetta (2014), have been included because of their potential endogeneity. Finally, it is important to point out that, in order to be fully consistent with the counterfactual framework, all the covariates related to the household composition have been computed including the migrant members (i.e., as if the migrants were present in the household).

Since the individual characteristics of the household head are relevant in explaining both households' economic performance and the migration decision, they have sometimes been included among matching covariates (Calero et al., 2009; Jimenez-Soto and Brown, 2012; Möllers and Meyer, 2014). However, we did not include any household head-related variable among matching 
covariates because, in the absence of pre-treatment information, the household headship should be considered endogenous to migration (Cox-Edwards and Rodríguez-Oreggia, 2009). In fact, the remarkable difference in the share of female-headed households between migrant and non-migrant groups (13.9\% vs. $44.7 \%$ ) can be largely explained by the fact that when the husband migrates his wife "inherits" the headship. In this regard, as pointed out by Hadi (2001), the migration-induced shift in the headship from the husband to the wife can contribute to women's empowerment. To the extent that it affects the level of per capita expenditure, however, this effect is captured by the ATT.

The educational attainment of the household members is a key predictor for both household expenditure and migration propensity (Sharma and Zaman, 2009). Since the returns and the average level of education significantly differ between males and females, this information has been disaggregated according to gender by including two covariates indicating the average years of schooling of female and male adult members respectively. However, the level of education of younger members has not been included because it is likely to be endogenous to migration. As before, these covariates have been computed as if migrant members were present in the household while HIES data on individual educational achievements have been converted into years of schooling following the information on Bangladesh education system provided by UNESCO (2011).

Nine out of ten of Bangladeshi households are Muslim and Islam is a pillar of national identity. Considering also that, except for a 'secularist' parenthesis during the rule of Mujibur Rahman, the country has historically pursued policies inspired by a moderate Islamism (Lewis, 2011), the correlation between the economic performance and household's religious beliefs comes as no surprise (Sharma and Zaman, 2009). Moreover, besides the purely economic channel, being Muslim could affect the probability of migration because the most important destinations are also Muslim countries. For these reasons - and because of its arguably clear exogeneity - the households' religious background has been included among predictors.

Besides the variables related to demographic structure and human capital endowment, migration literature also stresses the importance of households' local environment. In order to take it into account, we have included among the matching covariates a set of regional dummies, a dummy for households living in urban areas and a dummy for households living in one of the four metropoli$\tan$ areas. The inclusion of a dummy for households living in areas connected to the public electricity grid follows the same logic.

Members' entrepreneurial attitude is relevant in determining both the economic performance of the household and the probability of migrating. Moreover, it can be considered as a proxy for relevant unobservable characteristics. Building on HIES information about the type of businesses run by each household, we created dummies for household's involvement in both formal and informal non-agricultural business. To avoid endogeneity, we considered only the firms that were already active before the migration.

We also included in the model two variables related to land ownership. Even though land ownership could be endogenous to migration (e.g., land could have been sold for financing migration or, vice versa, could have been purchased with the remittances), the Bangladesh's land market is very tight (Mendola, 2008) and our dummies account only for the two extremes of land ownership: landlessness/quasi-landlessness and a large farm ownership.

Finally, following DuGoff et al. (2014) and Imbens and Rubin (2015), we have also included among matching covariates the sample weights, which contain relevant information on the individual observation, and some interaction terms and nonlinear transformations of the above discussed covariates.

The final specification of the probability model has been chosen following a stepwise approach. First, we started by including only the variables related to the household demographic structure and members' education level and then we added the other groups of variables, i.e. geographical variables, land ownership, etc. This procedure is shown in Table 2. As expected, almost all the 


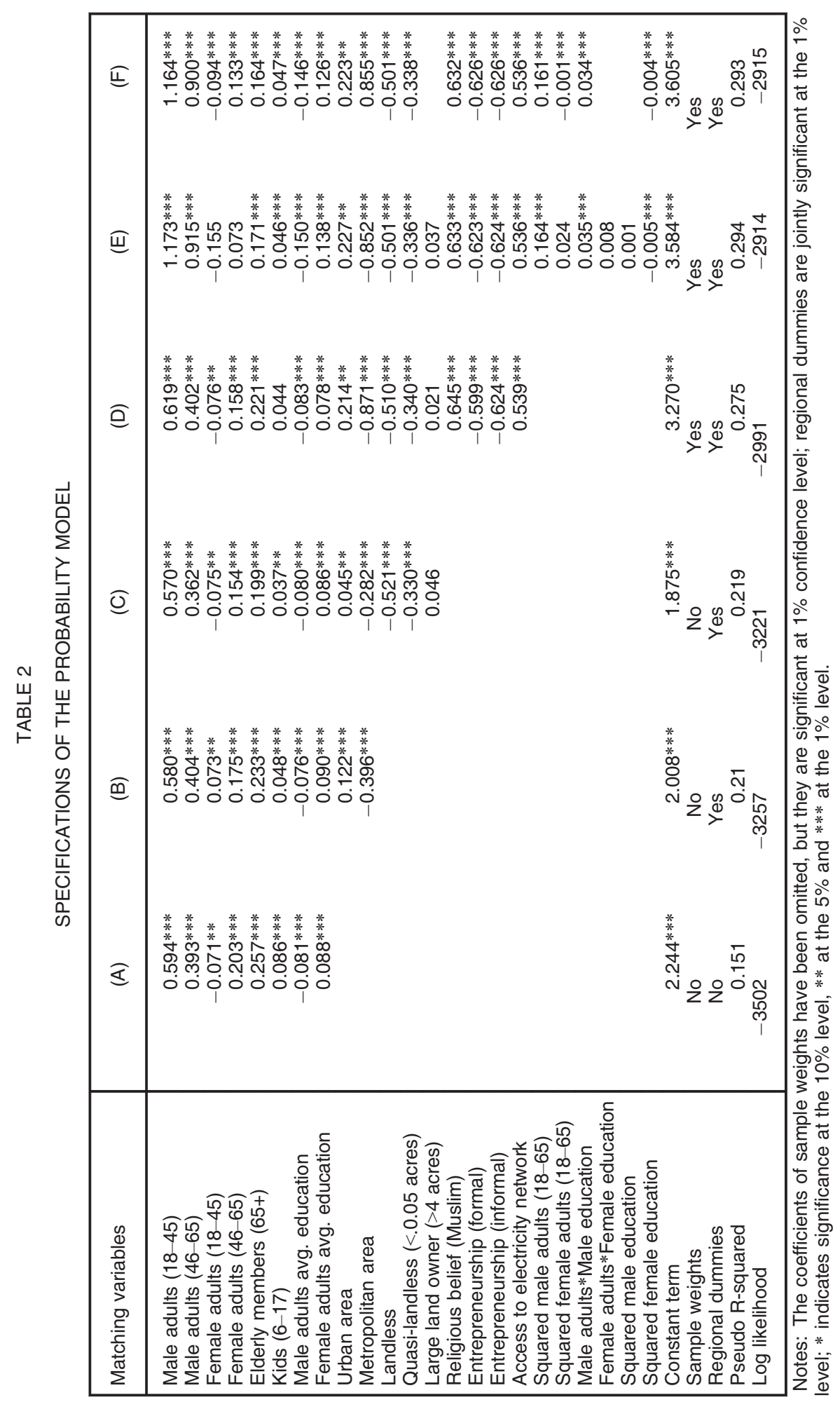


TABLE 3

MARGINAL EFFECTS OF SELECTED MATCHING COVARIATES ON THE PROBABILITY OF MIGRATION

\begin{tabular}{|c|c|c|c|c|}
\hline \multirow{2}{*}{\begin{tabular}{|l} 
Matching covariates \\
Male adults (18-45)
\end{tabular}} & \multirow{2}{*}{$\frac{d y / d x}{0.102}$} & \multicolumn{2}{|c|}{ [95\% Conf. Interval] } & \multirow{2}{*}{$\frac{\text { Mean }}{0.976}$} \\
\hline & & 0.089 & 0.115 & \\
\hline Male adults (46-65) & 0.079 & 0.067 & 0.091 & 0.338 \\
\hline Female adults (18-45) & -0.008 & -0.014 & -0.003 & 1.018 \\
\hline Female adults (46-65) & 0.012 & 0.004 & 0.019 & 0.304 \\
\hline Elderly $(65+)$ & 0.014 & 0.007 & 0.022 & 0.189 \\
\hline Kids $(6-17)$ & 0.004 & 0.001 & 0.007 & 1.289 \\
\hline Male adults' average education & -0.013 & -0.015 & -0.011 & 4.357 \\
\hline Female adults' average education & 0.011 & 0.009 & 0.014 & 3.627 \\
\hline Urban area & 0.020 & 0.003 & 0.036 & 0.268 \\
\hline Metropolitan area & -0.075 & -0.098 & -0.052 & 0.092 \\
\hline Religious belief (Muslim) & 0.055 & 0.043 & 0.068 & 0.878 \\
\hline Entrepreneurship (formal) & -0.055 & -0.070 & -0.040 & 0.063 \\
\hline Entrepreneurship (informal) & -0.055 & -0.065 & -0.045 & 0.182 \\
\hline Access to electricity network & 0.047 & 0.039 & 0.055 & 0.576 \\
\hline Landless & -0.044 & -0.061 & -0.026 & 0.063 \\
\hline Quasi-landless ( $<0.05$ acres) & -0.030 & -0.039 & -0.021 & 0.235 \\
\hline
\end{tabular}

Notes: marginal effects at means calculated with delta method; dy/dx indicates the marginal effect, the following two columns the lower and upper values of its $95 \%$ confidence interval wile the last column indicates the mean value of the covariates.

variables discussed above turn out to be significant in predicting the probability of selection into the treatment, and every group of variables significantly improves the statistical fit of the model. Model (F) represents our final specification and it is the probit model that we use to estimate the propensity score (and that, in theory, mimics the assignment mechanism of household migration in Bangladesh). From Table 3, which reports the marginal effects at the means of the most relevant covariates, it clearly emerges that the dimension of the household, and the number of working-age males in particular, is key in influencing migration decision. Specifically, having an additional male adult member increases the household probability of being migrant by either 10.2 or 7.9 percentage points, depending on his age group.

Consistent with previous discussion, the matching covariates of model $(\mathrm{F})$ and household per capita expenditure, i.e. the outcome variable, turn out to be highly correlated (Table 4). The correlation with the per capita expenditure indicates that, as long they are exogenous, the matching variables are relevant confounding factors. However, it is also worth dwelling on the coefficients of male adults: the presence of an additional member is correlated with a significantly higher level of expenditure $(+4.9 \%$ if he belongs to the age group $18-45,+13.3 \%$ if he is between 46 and 65 years old). As we will discuss in the following sections, the correlation between the number of male adult members, per capita expenditure and probability of migration is key in our argument that international migration might not represent a viable strategy for the poorest segments of the population.

\section{Robustness checks}

The estimation of counterfactual outcomes requires that every treated unit is matched with at least one control. This condition is met when the density function of the lps of treated units overlaps with the density function of lps of the untreated. The common support problem has been addressed by imposing a caliper on the matching estimator. ${ }^{8}$ When at least one of the predictors is not binary, the optimal caliper width should range between 0.2 and 0.55 the standard deviation of the lps (Austin, 2011). In our case, a caliper equal to 0.5 standard deviations of the lps allowed us to match 
TABLE 4

CORRELATION BETWEEN PER CAPITA EXPENDITURE AND MATCHING COVARIATES

\begin{tabular}{|l|c|}
\hline Variables & Log p.c. expenditure (modified OECD scale) \\
\hline Male adults (age 18-45) & $0.0486^{* * *}$ \\
Male adults (age 46-65) & $0.1331^{* * *}$ \\
Female adults (age 18-45) & $-0.0485^{* * *}$ \\
Female adults (age 46-65) & 0.0046 \\
Elderly (age 65+) & 0.0026 \\
Kids (age 6-17) & $0.0408^{* * *}$ \\
Average schooling of male adult members & $0.0117^{* * *}$ \\
Average schooling of female adult members & $0.0138^{* * *}$ \\
Urban area & $0.2319^{* * *}$ \\
Metropolitan area & $0.1625^{* * *}$ \\
Muslim & $0.0692^{* * *}$ \\
Formal sector entrepreneurship (before migration) & $0.1877^{* * *}$ \\
Informal sector entrepreneurship (before migration) & $0.0461^{* * *}$ \\
Access to public electricity & $0.2097^{* * *}$ \\
Sample weights & $0.0001^{* * *}$ \\
Landless & $-0.2359^{* * *}$ \\
Semi-landless & $-0.2049^{* * *}$ \\
Squared number of adults & $-0.0179^{* * *}$ \\
N. of male adults * Avg. male adult schooling & $0.0063^{* * *}$ \\
Squared female avg. schooling & $0.0022^{* * *}$ \\
Constant term & $9.9701^{* * *}$ \\
Regional dummies & $Y e s$ \\
Observations & 12,240 \\
R-squared & 0.4302 \\
\hline Notes: this table repors the correlation between the & \\
\hline
\end{tabular}

Notes: this table reports the correlation between the matching covariates of model $(F)$ and the level of household per capita expenditure; primary sampling unit clustered standard errors: ${ }^{* * *} p<0.1,{ }^{* *} p<0.05$, $* p<0.01$ (Regional dummies are jointly significant at the $1 \%$ level).

every treated unit. Our estimates have been obtained using a $\mathrm{NNM}(3)$ estimator with replacement, but they also hold using other matching algorithms, i.e. NNM(1), radius and kernel. ${ }^{9}$

The quality of the estimates depends on the balance of the conditioning covariates between the treated and matched control groups. Balance is achieved if the following condition is met:

$$
D_{i} \perp \mathbf{X}_{i} \mid \widehat{\ell}\left(\mathbf{X}_{i}\right) .
$$

Comparing the lps distribution before and after matching provides a first glance of achieved balancing (Figure 3). Following Sianesi (2004), the regression of the probability model has been repeated excluding the unmatched observations: none of the predictors turns out to be significant and the pseudo- $\mathrm{R}^{2}$ is very close to zero, confirming the balance. Finally, the balance of matching covariates is confirmed by the sizeable reduction of the average standardized bias (from $26.7 \%$ to $2.9 \%$ ), that is a weighted difference of the mean of the covariates between treatment and matched control groups (Figure 1).

\section{RESULTS AND POLICY IMPLICATIONS}

\section{Empirical results}

On average, international migration produces a positive and significant impact on the per capita expenditure of migrants' household members, though its magnitude depends on the assumptions on 
FIGURE 1

STANDARDISED BIAS OF THE MATCHING COVARIATES

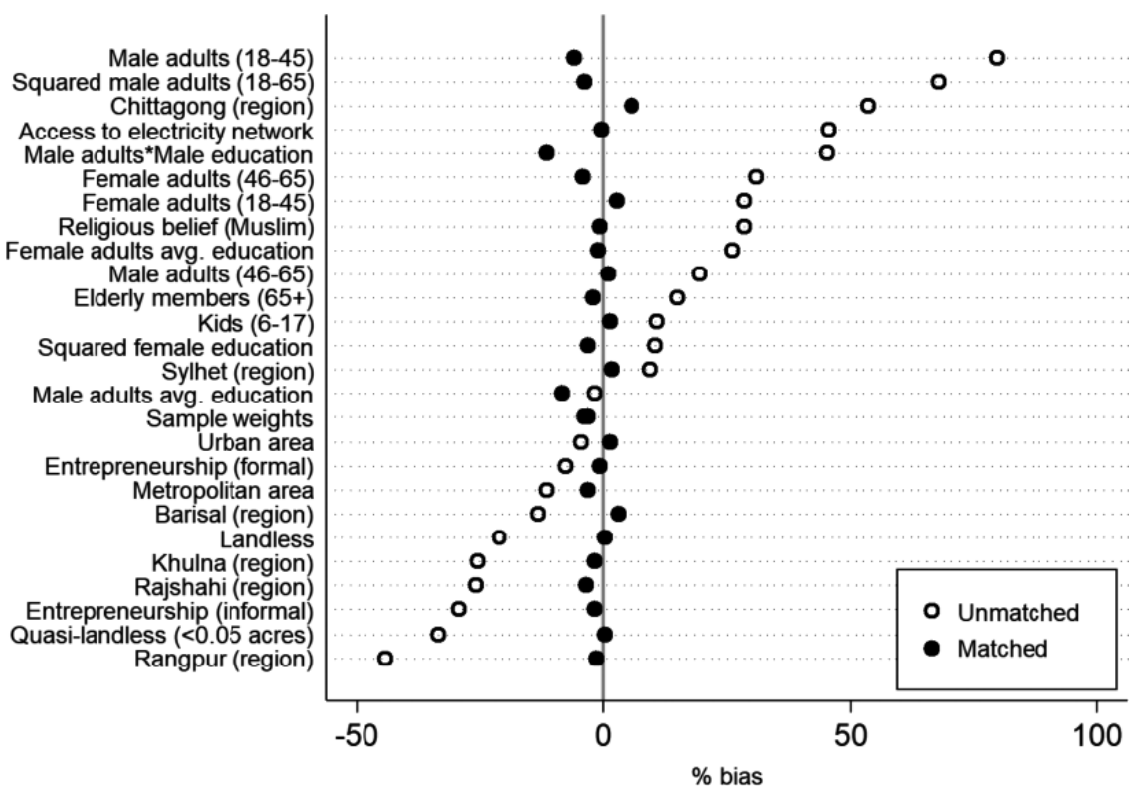

households' economies of scale (Table 5). These results, that are robust to a 50:50 cross-validation, to alternative specifications of the probability model and to different definitions of migrant households, ${ }^{10}$ are consistent with the hypothesis that migration is a decision made at the household level with a view to welfare improvement (Stark and Bloom, 1985; Stark and Lucas, 1988).

Quartile ATT, reported in Table 6, indicates that the impact of migration is higher for relatively poorer households while it is not statistically significant for the households originally belonging to the richest quartile. This may be due to the fact that international migrants originating from wealthy households have a low incentive to remit and because, by migrating, they forego relatively high domestic earnings.

TABLE 5

ATT OF INTERNATIONAL MIGRATION ON PER CAPITA EXPENDITURE ACCORDING TO DIFFERENT EQUIVALENCE SCALES

\begin{tabular}{|l|cc|}
\hline Equivalence scale & Sample ATT & Population ATT \\
\hline No equivalence scale & $0.309^{* * * *}$ & 0.288 \\
& $(0.022)$ & 0.286 \\
OECD (Oxford) scale & $0.307^{* * * *}$ & \\
& $(0.021)$ & 0.267 \\
OECD (modified) scale & $0.287^{* * *}$ & 0.175 \\
Squared root scale & $(0.021)$ & \\
& $0.190^{* * *}$ & $(0.021)$ \\
\hline
\end{tabular}

Note: *indicates significance at the $10 \%$ level, ** at the $5 \%$ and $* * *$ at the $1 \%$ level; Standard errors in parentheses; Equivalence scales as described in OECD (2013). 
TABLE 6

QUARTILE ATT

\begin{tabular}{|l|ccc|}
\hline Original quartile & Number of households & Sample Quartile ATT & Population Quartile ATT \\
\hline I & 55 & $0.648^{* * *}$ & 0.651 \\
II & 323 & $(0.094)$ & 0.522 \\
III & 546 & $0.552^{* * *}$ & 0.295 \\
IV & \multirow{2}{*}{367} & $0.045)$ & -0.081 \\
& & $(0.034)$ & \\
\hline
\end{tabular}

Note: $*$ indicates significance at the $10 \%$ level, $* *$ at the $5 \%$ and $* * *$ at the $1 \%$ level; Standard errors in parentheses; Modified OECD scale (OECD, 2013).

TABLE 7

ATT OVER TIME

\begin{tabular}{|l|ccc|}
\hline Years since migration & Number of households & Sample ATT over time & Population ATT over time \\
\hline Less than 2 & 210 & $0.142^{* * *}$ & 0.152 \\
2 & 228 & $(0.060)$ & 0.171 \\
3 & 170 & $0.161^{* * *}$ & 0.204 \\
4 & 105 & $(0.037)$ & $0.214^{* * *}$ \\
& & $(0.046)$ & 0.236 \\
5 & 88 & $0.304^{* * *}$ & 0.259 \\
6 or more & 355 & $(0.116)$ & 0.415 \\
Household with no & 135 & $0.335^{* * *}$ & 0.349 \\
current migrants but & & $0.441^{* * *}$ & \\
with a returnee & & $(0.048)$ & $0.354^{* * *}$ \\
\hline
\end{tabular}

Note: $*$ indicates significance at the $10 \%$ level, **at the $5 \%$ and $* * *$ at the $1 \%$ level; Standard errors in parentheses; Modified OECD scale (OECD, 2013).

The disaggregation of the ATT with length of staying abroad (Table 7) shows that the per capita expenditure increases with the length of the treatment period, a result that may have different explanations. It is possible, for example, that migrant households use part of the remittances for investment purposes. However, it is also possible that the earning capacity of migrants increases over time and therefore they are able to remit more. On the other hand, the result could merely reflect the self-selection of positive migration experiences.

The non-parametric estimation of the counterfactual scenario also allows us to investigate the impact of migration on social mobility and inequality. Social mobility was captured building a transition matrix linking migrant households' observed outcomes to their estimated counterfactuals (Table 8). The matrix shows that migration is a risky strategy but, when successful, it guarantees a significant improvement of household members' relative well-being. On average, about half of migrant households have been able to climb the social ladder, moving to a higher expenditure quintile. On the other hand, however, in about one out of four cases migration implied a worsening of 
TABLE 8

VARIATION OF MIGRANT HOUSEHOLDS' RANKING IN THE EXPENDITURE DISTRIBUTION: TRANSITION MATRIX FROM COUNTERFACTUAL (NO MIGRATION) TO OBSERVED SCENARIO

\begin{tabular}{|c|c|c|c|c|c|}
\hline \multirow[b]{2}{*}{ Counterfactual scenario quintile (no migration) } & \multicolumn{5}{|c|}{ Observed scenario quintile (migration) } \\
\hline & I & II & III & IV & $\mathrm{V}$ \\
\hline I & $0.5 \%$ & $0.4 \%$ & $0.4 \%$ & $0.3 \%$ & $0.7 \%$ \\
\hline ॥ & $0.9 \%$ & $1.7 \%$ & $4.0 \%$ & $4.6 \%$ & $6.9 \%$ \\
\hline III & $0.7 \%$ & $3.6 \%$ & $4.5 \%$ & $9.7 \%$ & $11.9 \%$ \\
\hline IV & $1.0 \%$ & $2.9 \%$ & $6.7 \%$ & $9.9 \%$ & $13.7 \%$ \\
\hline $\mathrm{V}$ & $0.4 \%$ & $2.2 \%$ & $2.5 \%$ & $3.7 \%$ & $6.1 \%$ \\
\hline
\end{tabular}

Note: Percentage of households on diagonal: $22.7 \%$.

Percentage of households that moved up by at least one quintile (migration success): $52.6 \%$.

Percentage of households that moved down by at least one quintile (migration failure): $24.7 \%$.

Modified OECD scale (OECD, 2013); Sample weights included.

the household's economic conditions. This latter result may be explained by the fact that migration requires a substantial upfront investment, which households often finance through borrowing; and if the gains from migration are lower than expected, they may need years to repay it (Rahman, 2015; Das et al., 2019).

Finally, looking at marginal distributions, it emerges that international migration only marginally involves the poorest segments of Bangladesh's population (Table 9): about four out of five migrants come from relatively better-off households (i.e., households belonging to the third, fourth or fifth quintile) while less than three per cent of them originate from households belonging to the poorest quintile.

International migration increases inequality by 1.58 Gini points (Table 10). This qualitative result is consistent with the findings of Brown and Jimenez (2008) and Barham and Boucher (1998), but in our case the increase in Gini points is smaller and not statistically significant at conventional confidence levels.

\section{Policy implications}

Over the last couple of decades, the government of Bangladesh and several NGOs have pursued policies aimed at favouring outwards migration. For example, the Ministry of Expatriates' Welfare and Overseas Employment was established in 2001 for helping Bangladeshi workers to find a job abroad. ${ }^{11}$ The Probashi Kallyan Bank, established in 2010, is a public bank aiming at lending subsidized credit to international migrants. Similarly, BRAC and other NGOs provide loans and guidance services to migrants. Moreover, the government adopted policies aimed at reducing the cost to remit through formal channels.

Our analysis finds a significant and positive effect of migration on household welfare but, for a number of reasons, it also raises some concerns regarding the effectiveness of pro-migration and pro-remittances policies in helping the most in need. Indeed, as shown in Figure 2, there is virtually no difference in the distribution of per capita expenditure of the observed and the counterfactual scenarios below the poverty threshold of 1 US Dollar per day. This is because nearly all of the households belonging to the lowest expenditure quintile fall outside the overlapping region and therefore our analysis is agnostic about the potential effect that migration would have on their welfare. 
TABLE 9

QUINTILE DISTRIBUTION OF MIGRANT HOUSEHOLDS

\begin{tabular}{|c|c|c|c|c|}
\hline \multirow[b]{2}{*}{ Expenditure quintiles } & \multicolumn{2}{|c|}{$\begin{array}{l}\text { Quintile to which migrant } \mathrm{HH} \\
\text { belong (marginal distributions of } \\
\text { transition matrix) }\end{array}$} & \multicolumn{2}{|c|}{ Relative frequency of migrant $\mathrm{HH}$} \\
\hline & Observed & Counterfactual & Observed & Counterfactual \\
\hline I & $3.15 \%$ & $2.64 \%$ & $1.63 \%$ & $1.37 \%$ \\
\hline II & $10.55 \%$ & $16.52 \%$ & $5.46 \%$ & $8.55 \%$ \\
\hline III & $18.05 \%$ & $27.17 \%$ & $9.35 \%$ & $14.08 \%$ \\
\hline IV & $28.07 \%$ & $37.73 \%$ & $14.53 \%$ & $19.55 \%$ \\
\hline V & $40.19 \%$ & $15.94 \%$ & $20.82 \%$ & $8.26 \%$ \\
\hline
\end{tabular}

Note: Modified OECD scale (OECD, 2013); Sample weights included.

TABLE 10

COMPARISON OF GINI INDEXES: OBSERVED VS. COUNTERFACTUAL

\begin{tabular}{|l|ccc|}
\hline Scenario & Gini index & Lower bound (95\%) & Upper bound (95\%) \\
\hline Observed (migration) & 33.15 & 31.22 & 35.01 \\
Counterfactual (no migration) & 31.57 & 29.63 & 33.52 \\
\hline
\end{tabular}

Note: Modified OECD scale (OECD, 2013); Sample weights included.

FIGURE 2

PER CAPITA EXPENDITURE DENSITY FUNCTION (LEFT TAIL): OBSERVED VS. COUNTERFACTUAL



Importantly, most of the characteristics that seem to determine the migration decision (e.g., the number of working-age male members) cannot be influenced by any policy intervention. For example, as evident from Figure 1 and from Table 3, smaller households are less likely to engage in international migration. This comes as no surprise, considering that the migration of a male adult 
member may well entail more costs than gains in the short-run for single-parent households or households consisting of two adults and two-three young children. In such cases the availability of subsidized loans or other pro-migration policies might not be enough to change the household's incentive to migrate. ${ }^{12}$

Furthermore, the demographic structure of the households influences not only the probability of migration but also affects household economic vulnerability. In fact, HIES 2010 indicates that small households with young children are the most vulnerable group. ${ }^{13}$ These households are not likely to engage in migration in the near future and therefore they are not likely to benefit directly from pro-migration policies. Hence, even though migration policies might benefit some group of poor households, they may fail to helping those most in need.

These results have important policy implications. On the one hand, policies that encourage workers' migration and remittances may significantly contribute to increase the average household welfare and triggering economic growth. On the other hand, such policies cannot be seen as a substitute for more specific pro-poor interventions.

\section{CONCLUSIONS}

This research explores the impact of international migration on the welfare of migrant's left-behind households in Bangladesh. Migration turns out to have a significant and positive impact on the average welfare of migrants' family members, a result proven robust to different assumptions regarding households' economies of scale. Quartile ATT shows that the effect on per capita expenditure is stronger for the households belonging to the first expenditure quartile and decreasing with expenditure, although it is not statistically significant for the households belonging to the fourth quartile. Most migrants, however, come from households belonging to the third and fourth expenditure quintiles, whereas only less than three per cent are from the poorest one. The counterfactual scenario also suggests that migration might produce a modest but negative effect on inequality, though not statistically significant.

In general, international migration appears to be a household strategy characterized by high expected return and significant risk for Bangladeshi households (Das et al., 2019). Indeed, by taking social mobility as a yardstick for the success of migration, it turns out that in about half of the cases migrant households are able to climb the social ladder but, on the other hand, one fourth of migrant households experience a worsening of their welfare.

Finally, since many of the characteristics that determine the probability of migration cannot be influenced by policymakers and are also negatively correlated with the pre-migration economic conditions of the households, the analysis argues that pro-migration policies may not be an effective strategy to lift out of poverty the most in need.

\section{NOTES}

1. Consumption, proxied by per capita expenditure, allows us to map welfare into a mono-dimensional money-metric measure that is less prone to measurement error and less volatile than income.

2. The OECD Oxford scale assigns a weight of 1 to the first household member, of 0.7 to each additional adult member and of 0.5 to each child. The OECD modified scale is similar but the weights are $1,0.5$ and 0.3 respectively. In the square root scale, the level of household expenditure is divided by the square root of the household size.

3. The 2001 Census and previous HIES waves did not included specific modules on migration.

4. However, McKenzie et al. (2010) also point out that matching is not always able to fully remove the bias and argue that selection on observables might still represent an issue. On the other hand, it should be noted 
that their implementation of propensity score matching is not fully satisfactory. Indeed, all their specifications include only variables related to the individual migrants but no information on the households of origin. Clearly, overlooking the relevance of household characteristics in determining individuals' migration decisions is not fully consistent with the idea, prevalent in the literature, that migration is a decision taken at the household level. The specification adopted in this study, on the other hand, includes several variables related to household socio-demographics that can reasonably be considered exogenous to the treatment(s) and, at the same time, turn out to be significantly correlated with both the outcome variables and the probability of migration (cf. "The selection of matching covariates" subsection).

5. Conversely, linear regression employs all the observations and controls only for the equality of the expected values of the covariates.

6. Formally: $\left(\mathrm{Y}_{i}^{(0)}, \mathrm{Y}_{i}^{(1)}\right) \Perp \mathrm{D}_{i} \mid e\left(\mathbf{X}_{i}\right)$, where $e\left(\mathbf{X}_{i}\right)$ indicates a generic balancing score.

7. Bertoli and Murard (2019) have recently pointed out that household composition may endogenously change with migration. In particular, with reference to the Mexican case, they found that migrant households are more likely to receive new members in the months which follow the migration episode. As a robustness check, we tested this hypothesis in Table 11 in the Appendix. Should the household recomposition be endogenous to migration, we would find at the level of primary sampling unit a positive association between average household size and proportion of migrant households. However, as shown in Table 11, there is no robust evidence of such association. Specifically, the point estimates of "Share of migrant households" are positive but not statistically different from 0 at conventional confidence levels: the coefficients' $p$-value is $9.4 \%$ in specification (1), which includes only regional and urban/metropolitan/ rural fixed effects, and rises to $13.5 \%$ in specification (2), where the two fixed effects are interacted (for a total of 17 fixed effects). These results mitigate the concern that endogenous household recomposition represents a major threat to our estimates.

8. The caliper is the maximum distance between two units in order to be considered "close enough" for matching. The use of a fixed caliper (and, in general, of linear distance measures) makes sense only if the propensity score has been linearized.

9. Table 12 in the Appendix shows that the results are not significantly affected by the choice of the matching estimator. Therefore, we have opted for NNM because this estimator allows an easier identification of the weights attached to each matched control (i.e., the NNM weights are always integers), to be used in building the counterfactual scenario.

10. As robustness check, Table 13 in the Appendix reports the results of the impact of migration without the households with returned migrants. The results are close to those including returnees.

11. Specifically, the Ministry is responsible for "formulating policies, plans, enacting laws, rules and regulations, developing projects, programmes and monitoring relating to the management of overseas employment as well as overall welfare of expatriate workers".

12. Moreover, as emphasized by Beam et al. (2016), unilateral facilitation policies related to information, job search, and documentation assistance are not sufficient to increase rates of international labor migration. There is evidence of multiple remaining barriers on both the supply side (e.g. relatively low interest on the part of potential migrants) and the demand side (e.g. highly selective job offers) for overseas work.

13. The households belonging to the poorest quintile have the lowest number of adults, the lowest number of kids between 7 and 17 years old but the highest number of children below the age of 6 .

\section{REFERENCES}

Acosta, P.

2011 "School attendance, child labour, and remittances from international migration in El Salvador", Journal of Development Studies, 47(6): 913-936.

Adams, R.H.

2011 "Evaluating the economic impact of international remittances on developing countries using household surveys: A literature review", Journal of Development Studies, 47(6): 809-828.

Adams, R.H. and A. Cuecuecha

2013 "The impact of remittances on investment and poverty in Ghana", World Development, 50: 24-40. Antman, F.M.

2015 "Gender discrimination in the allocation of migrant household resources", Journal of Population Economics, 28(3): 565-592. 
Asadullah, M.N., A. Savoia, and W. Mahmud

2014 "Paths to development: Is there a Bangladesh surprise?", World Development, 62: 138-154.

Austin, P.C.

2011 "Optimal caliper widths for propensity-score matching when estimating differences in means and differences in proportions in observational studies", Pharmaceutical statistics, 10(2): 150-161.

Azzarri, C. and A. Zezza

2011 "International migration and nutritional outcomes in Tajikistan", Food Policy, 36(1): 54-70.

Bangladesh Bank

2013 Of changes and transformations. Www.bb.org.bd/pub/special/chngtrnsform.pdf

Barham, B. and S. Boucher

1998 "Migration, remittances, and inequality: Estimating the net effects of migration on income distribution", Journal of development economics, 55(2): 307-331.

Beam, E., D. McKenzie, and D. Yang

2016 "Unilateral facilitation does not raise international labor migration from the Philippines", Economic Development and Cultural Change, 64(2): 323-68.

Bertoli, S. and F. Marchetta

2014 "Migration, remittances and poverty in Ecuador", Journal of Development Studies, 50(8): 10671089.

Bertoli, S. and E. Murard

2019 "Migration and co-residence choices: Evidence from Mexico", Journal of Development Economics, forthcoming.

Böhme, M.H., R. Persian, and T. Stöhr

2015 "Alone but better off? Adult child migration and health of elderly parents in Moldova", Journal of Health Economics, 39: 211-227.

Brown, R.P. and E. Jimenez

2008 "Estimating the net effects of migration and remittances on poverty and inequality: Comparison of Fiji and Tonga", Journal of International Development, 20(4): 547-571.

Calero, C., A.S. Bedi and R. Sparrow

2009 "Remittances, liquidity constraints and human capital investments in Ecuador", World Development, 37(6): 1143-1154.

Carletto, C., K. Covarrubias and J.A. Maluccio

2011 "Migration and child growth in rural Guatemala", Food Policy, 36(1): 16-27.

Chowdhury, M.B.

2011 "Remittances flow and financial development in Bangladesh", Economic Modelling, 28(6): 26002608.

Combes, J.L., C. Ebeke, M.N. Etoundi, et al.

2014 "Are foreign aid and remittance inflows a hedge against food price shocks in developing countries?", World Development, 54(1): 81-98.

Cox, D.R.

1992 "Causality: Some statistical aspects", Journal of the Royal Statistical Society. Series A (Statistics in Society), 291-301.

Cox-Edwards, A. and E. Rodríguez-Oreggia

2009 "Remittances and labor force participation in Mexico: An analysis using propensity score matching", World Development, 37(5): 1004-1014.

Das, N., A. de Janvry, A. Mahmood, et al.

2019 "Migration as a risky enterprise: A diagnostic for Bangladesh", International Migration Review, forthcoming.

De Haas, $\mathrm{H}$.

2012 "The migration and development pendulum: A critical view on research and policy", International Migration, 50(3): 8-25.

Deaton, A. and S. Zaidi

2002 Guidelines for constructing consumption aggregates for welfare analysis, LSMS Working Paper No. 135, The World Bank, Washington. 
DuGoff, E.H., M. Schuler, and E.A. Stuart

2014 "Generalizing observational study results: Applying propensity score methods to complex surveys", Health Services Research, 49(1): 284-303.

Gardner, K.

2009 "Lives in motion: The life-course, movement and migration in Bangladesh", Journal of South Asian Development, 4(2): 229-251.

Giannelli, G.C. and L. Mangiavacchi

2010 "Children"s schooling and parental migration: Empirical evidence on the "Left-behind" Generation in Albania", Labour, 24(1): 76-92.

Graham, E., L.P. Jordan, and B.S. Yeoh

2015 "Parental migration and the mental health of those who stay behind to care for children in SouthEast Asia", Social Science and Medicine, 132: 225-235.

Hadi, A.

2001 "International migration and the change of women"s position among the left-behind in rural Bangladesh", International Journal of Population Geography, 7(1): 53-61.

Ham, J.C., X. Li, and P.B. Reagan

2011 "Matching and semi-parametric IV estimation, a distance-based measure of migration, and the wages of young men", Journal of Econometrics, 161(2): 208-227.

Hassan, G.M., M. Chowdhury and M. Bhuyan

2016 "Growth effects of remittances in Bangladesh: Is there a U-shaped relationship?", International Migration, 54(5): 105-121.

Imbens, G.W. and D.B. Rubin

2015 Causal inference in statistics, social, and biomedical sciences. Cambridge University Press, New York.

Jimenez-Soto, E.V. and R.P. Brown

2012 "Assessing the poverty impacts of migrants" remittances using propensity score matching: The case of Tonga", Economic Record, 88(282): 425-439.

Karamba, W.R., E.J. Quiñones, and P. Winters

2011 "Migration and food consumption patterns in Ghana", Food Policy, 36(1): 41-53.

Kumar, R.R. and P.J. Stauvermann

2014 "Exploring the nexus between remittances and economic growth: A study of Bangladesh", International Review of Economics, 61(4): 399-415.

Lewis, D.

2011 Bangladesh: Politics, economy and civil society. Cambridge University Press, Cambridge.

Lokshin, M., M. Bontch Osmolovski, and E. Glinskaya

2010 "Work-Related migration and poverty reduction in Nepal", Review of Development Economics, 14 (2): 323-332.

Mahmud, W.

2008 "Social development in Bangladesh: Pathways, surprises and challenges", Indian Journal of Human Development, 2(1): 79-92.

Mangiavacchi, L., F. Perali, and L. Piccoli

2018 "Intrahousehold distribution in migrant-sending families", Journal of Demographic Economics, 84 (1): 107-148.

McKenzie, D. and H. Rapoport

2011 "Can migration reduce educational attainment? Evidence from Mexico", Journal of Population Economics, 24(4): 1331-1358.

McKenzie, D., S. Stillman, and J. Gibson

2010 "How important is selection? Experimental vs. non-experimental measures of the income gains from migration", Journal of the European Economic Association, 8(4): 913-945.

Mendola, M.

2008 "Migration and technological change in rural households: Complements or substitutes?", Journal of Development Economics, 85(1): 150-175.

Mendola, M. and C. Carletto

2012 "Migration and gender differences in the home labour market: Evidence from Albania", Labour Economics, 19(6): 870-880. 
Mohapatra, S., D. Ratha, and A. Silwal

2010 “Outlook for remittance flows 2011-12”, World Bank Migration and Development Brief, $13: 1-14$.

Möllers, J. and W. Meyer

2014 "The effects of migration on poverty and inequality in rural Kosovo", IZA Journal of Labor and Development, 3(1): 16.

Nguyen, M.C. and P. Winters

2011 "The Impact of migration on food consumption patterns: The case of Vietnam", Food Policy, 36 (1): 71-87.

OECD

2013 OECD framework for statistics on the distribution of household income, consumption and wealth. OECD Publishing. https://doi.org/10.1787/9789264194830-en.

Rahman, M.M.

2015 "Migrant indebtedness: Bangladeshis in the GCC countries", International Migration, 53(6): 205219.

Rubin, D.B.

2001 "Using propensity scores to help design observational studies: Application to the tobacco litigation", Health Services and Outcomes Research Methodology, 2(3): 169-188.

Sharma, M., and H. Zaman.

2009 "Who migrates overseas and is it worth their while? An assessment of household survey data from Bangladesh", Policy Research Working Paper Series 5018, World Bank, Washington, DC.

Sianesi, B.

2004 "An evaluation of the Swedish system of active labor market programs in the 1990s", The Review of Economics and Statistics, 86(1): 133-155.

Siddique, A., E.A. Selvanathan and S. Selvanathan

2012 "Remittances and economic growth: Empirical evidence from Bangladesh, India and Sri Lanka", Journal of Development Studies, 48(8): 1045-1062.

Siddiqui, $\mathrm{T}$.

2003 "Migration as a livelihood strategy of the poor: the Bangladesh case". Refugee and Migratory Movements Research Unit, Dhaka University.

Sikder, M.J.U. and V. Higgins

2017 "Remittances and social resilience of migrant households in rural Bangladesh", Migration and Development, 6(2): 253-275.

Stark, O. and D.E. Bloom

1985 "The new economics of labor migration", The American Economic Review, 75(2): 173-178.

Stark, O. and R.E. Lucas

1988 "Migration, remittances, and the family", Economic Development and Cultural Change, 465-481.

The Economist

2012 "The path through the fields", November $3^{\text {rd }}$. print edition.

UNESCO.

2011 World data on education, $7^{\text {th }}$ edition, 2010/11 - Bangladesh. Http://unesdoc.unesco.org/images/ 0021/002112/211299e.pdf.

United Nations.

2013 International Migration Report 2013. Www.un.org/en/development/desa/population/publications/mi gration/migration-report-2013.shtml.

Wickramage, K., C., Siriwardhana, P., Vidanapathirana, et al.

2015 "Risk of mental health and nutritional problems for left-behind children of international labor migrants", BMC psychiatry, 15(1), 39. 


\section{APPENDIX}

TABLE A1

CORRELATION BETWEEN AVERAGE HOUSEHOLD SIZE AND SHARE OF MIGRANT HOUSEHOLDS

\begin{tabular}{|l|ll|}
\hline & \multicolumn{2}{c|}{ Household size } \\
\cline { 2 - 3 } & \multicolumn{1}{|c|}{$(1)$} & $(2)$ \\
\hline VARIABLES & & 0.2915 \\
Share of migrant households & $0.315^{*}$ & $(0.1883)$ \\
& $(0.1875)$ & No \\
Urban/Metropolitan/Rural fixed effects & Yes & No \\
Regional fixed effects & Yes & 612 \\
Regional * Urban/Metropolitan/Rural fixed effects & No \\
Observations & 612 & 0.3353 \\
R-squared & 0.3164 & \\
\hline
\end{tabular}

Note: This table reports the correlation between the average household size and the share of migrant household across HIES's primary sampling units; the number of parameters estimated in (1) and (2) are 9 and 18 respectively; robust standard errors in parentheses: $* * * p<0.1, * * p<0.05, * p<0.01$.

TABLE A2

ATT OF INTERNATIONAL MIGRATION (DIFFERENT MATCHING ESTIMATORS)

\begin{tabular}{|l|rrrrr|}
\hline Sample & Treated & Controls & ATT & S.E. & t-stat \\
\hline Unmatched (Naive) & 10.7506 & 10.3421 & 0.4086 & 0.0162 & 25.22 \\
Matched (NNM(3)) & 10.7506 & 10.4450 & 0.3056 & 0.0231 & 13.23 \\
Matched (NNM(1)) & 10.7506 & 10.4484 & 0.3022 & 0.0269 & 11.22 \\
Matched (Kernel) & 10.7502 & 10.4326 & 0.3176 & 0.0202 & 11.94 \\
Matched (Radius) & 10.7506 & 10.4484 & 0.3022 & 0.0253 & 11.94 \\
\hline
\end{tabular}

Note: This table reports the estimates of the ATT of international migration on household p.c. expenditure obtained by means of different matching estimators; p.c. expenditure calculated using the Oxford equivalence scale.

TABLE A3

ATT OF MIGRATION CONSIDERING AS MIGRANT ONLY HOUSEHOLDS HAVING A MEMBER CURRENTLY ABROAD (I.E., NOT CONSIDERING RETURNED MIGRANTS)

\begin{tabular}{|l|c|}
\hline Equivalence scale & Sample ATET \\
\hline No equivalence scale & $0.342 * * *$ \\
OECD (Oxford) scale & $(0.0235)$ \\
& $0.339 * *$ \\
OECD (modified) scale & $(0.0228)$ \\
& $0.319 * * *$ \\
Squared root scale & $(0.0226)$ \\
& $0.221 * * *$ \\
& $(0.0229)$ \\
\hline
\end{tabular}

Note: Standard errors in parentheses: * indicates significance at the $10 \%$ level, ** at the $5 \%$ and $* * *$ at the $1 \%$ level; Modified OECD scale (OECD, 2013). 
FIGURE A1

DISTRIBUTION OF LINEARIZED PROPENSITY SCORE

Unmatched
